\title{
FIVE YEARS STUDY OF MORTALITY AND MORBIDITY PATTERNS OF TETANUS CASES IN A TERTIARY CARE PICU (PEDIATRIC INTENSIVE CARE UNIT), MULTAN PAKISTAN.
}

1. MBBS, FCPS

Associate Professor

CHC \& ICH Multan Pakistan.

2. MBBS, MCPS, DCH, FCPS

Professor

Department of Pediatrics

QAMC/BVH, Bahawalpur.

3. MBBS, FCPS

Assistant Professor

$\mathrm{CHC} \& \mathrm{ICH}$ Multan Pakistan.

4. MBBS, FCPS

Professor

Department of Pediatrics

CHC \& ICH Multan Pakistan.

Correspondence Address:

Dr. Asim Khurshid

House No.72, Nasheman Colony,

Bosan Road, Multan.

asimkhurshiddr@gmail.com

Article received on:

21/12/2018

Accepted for publication:

19/06/2019

\section{INTRODUCTION}

A significant decline in the incidence of tetanus is accounted from around the globe but in numerouscountries, it represents a huge threat. ${ }^{1}$ In Pakistan, immunization isn't accessible to many for different reasons. Mortalityfrom tetanus approaches close to $50 \%$ in developing countries like Pakistan. ${ }^{1,2}$

In Pakistan, Tetanus is a non-reportableailment and its incidence is not well archived. Prophylaxis against tetanus desiresimmunization with tetanus toxic and methods to accomplish good wound hygiene. ${ }^{3}$ Variation in death rates from tetanus is seen credited to variety in access to proper medical care. ${ }^{3}$

Clostridium tetani is the reason for Tetanus. It collects a solid neurotoxin tetanospasmin which interferes with the CNS. ${ }^{4}$ Tetanus is for all intents and purposes entirely preventable through vaccination. Worldwide frequency of tetanus is $\sim 1$ million cases every year with case casualty extending $20-50 \% .^{5}$

Tetanus occurs sporadically affecting either non-vaccinated or those who are incompetent to uphold their immunity statusthrough booster doses of vaccine. Vaccination at an earlier agehas been advocated to improve immunity to counter tetanussucceedingwell-timedboosters. ${ }^{6,7}$ Tetanus is a noncontiguous, ${ }^{8}$ classically exhibits as lockjaw, difficulty in swallowing, risussardonicus and neck stiffness. ${ }^{9}$

Management comprise of the avoidanceof Tetanus Toxin absorption, symptomatic treatment, antibiotics to eradicate the remaining organism andcare of wound. Severe advanced tetanus cases call forcare with sedation, airway protection and well-ordered ventilation. ${ }^{10,11}$ Autonomic dysfunction is common with events of tachycardia, raised blood pressure and sweating. ${ }^{12}$ Fatigue, asphyxia, aspiration pneumonia and autonomic 
nervoussystem variability are recognized to be the roots of death with tetanus. ${ }^{13-15}$

Acute penetrating skin damage is the commonest feature of tetanus cases ${ }^{5}$, while ulcers, snake bite, burns, gangrene, otitis media, child birth, IM/ IV injections and surgical procedures have also been associated with tetanus. ${ }^{16}$

Outbreaks of tetanus linked to injuries from natural calamities (like earth quakes and tsunamis) are well documented. ${ }^{17-21}$ Tetanus is still endemic in Pakistan especially amongst therural areas. Thefrequency andmortality related to tetanus is highin several studies conducted in different parts of Pakistan. ${ }^{22-25}$

Inadequacy of knowledge and absence of education donate to perceptions about risk factorsand fatality caused by tetanus in Pakistan. Our aim was to share our five year experience of demographic, clinical features, outcome and complications of tetanus patients admitted in Pediatric Intensive Care Unit (PICU).

\section{METHODS}

A total of 77 children were admitted in PICU (as per hospital admission policy) with the clinical diagnosis compatible with tetanus. All were aged between 1 month to 15 years. Public tertiary care hospital of Multan, Pakistan, was the place for this study from $1^{\text {st }}$ January 2013 to $31^{\text {st }}$ December 2017 cases. Known cases of epilepsy, with significant cardiac dysfunction, hepatic, respiratory or renal impairment were excluded. Patients who did not consent for the study or lost follow-up were also excluded. Detailed history was taken and thorough examination was done along with investigations. Diagnosis was made and patients or their attendants were explained about the diagnosis and treatment. Severity of tetanus was classified according tothe system reported by Ablett. ${ }^{4}$

Special focus was on care of wound, antibiotics and anticonvulsants use (as per ward criteria). Active immunization was also completed. Patients of grade II, III \& IV tetanus were admitted in PICU.
Avoidance to light and noise were maintained by keeping children in isolation room of PICU along with aseptic measures.

All patients were kept on nothing orally, IV fluids started with partial parental nutrition or TPN started as required. Nasogastric tube \& Foleys catheter passed. Patients with Grade I Tetanus were not shifted in PICU, they were kept ingeneral ward \& put on liquid diet so they were not included in the study. Debridement of wound was performed in patients with contaminated wound followed by daily dressing. Patients who developed hypoxia were given Oxygen orventilator support. In patients with uncontrolled fits, tracheotomy was made. Patients were discharged from hospital once they tolerated feed well \& their spasm or fits werecontrolled on oral medication. Follow-up visitswere advised at 10 days, 1 \& 3 months.

Data was collected on preformed forvariables related to demography, clinical details, stage of presentation, co morbid illness, site ofinjury \& history of tetanus vaccination, incubation period, management, outcome and complications. The data were analyzed using SPSS version 16. Descriptive statistics were appliedon demographic variables like age, gender. Qualitative variables were presented as Mean andstandard deviation like age. Qualitative variables were presented in percentage and frequencies like incubation period, co morbid illnesses, complication and mortality.

\section{RESULTS}

Out of a total of 77 cases of tetanus, 62 (80.6\%) were male and 15 (19.4\%) female. Majority, 44 $(57.1 \%)$ were between $2-7$ years. Twenty five (32.4\%) had no vaccination, $52(67.6 \%)$ partly vaccinated. We noted that not even a single case had proper vaccination (as required for age).

Otogenic tetanus was found in children of 2-7 years. A total of 44 had post injury tetanus, 30 had lower limbs affected. No identifiable portal of entry was noted in the remaining cases.

Mean incubation period (IP) of 5 days was found in post trauma children. Stiffness of the body, 
locked jaw and difficulty in swallowing turned out to be the most frequent complaints. Most children, 40 (51.9\%) belonged to grade III, 16 $(20.7 \%)$ grade IV while zero grade I.

Alteration in sensorium was not noted in most cases (65). Regarding the outcome, 62 (80.5\%) cases were shifted to ward and 15 (19.5\%) expired mostly of grade IV.

Less than 72 hours was the time for onset in all severe cases. Majority, 42 (54.5\%) stayed for more than 3 weeks and 5 (6.5\%) for more than 6 weeks.

Intubation was done 18 (23.4\%). Average duration of 12 days was noted for mechanical ventilation (10-14 days). During PICU stay, sixteen (20.8\%) had autonomic instability which desired isotropic supports. For complications, LRTI was reported in $15(19.4 \%)$, hypotension in 25 (32.4\%), AKI (accordingto rifle criteria) in 15 (19.4\%), sepsis in 18 (23.3\%), paralytic illus in 35 (45.4\%).

\begin{tabular}{|c|c|c|}
\hline \multicolumn{2}{|l|}{ Characteristics } & \multirow{2}{*}{$\begin{array}{c}\text { No. of Cases (\%) } \\
62(80.6 \%)\end{array}$} \\
\hline Gender & Male & \\
\hline ? & Female & $15(19.4 \%)$ \\
\hline \multirow{3}{*}{ Age (years) } & $<2$ years & $5(6.4 \%)$ \\
\hline & $2-7$ years & $44(57.1 \%)$ \\
\hline & $>7$ years & $28(36.3 \%)$ \\
\hline \multirow{2}{*}{ Vaccination Status } & Unvaccinated & $25(32.4 \%)$ \\
\hline & Partially vaccinated & $52(67.6 \%)$ \\
\hline \multirow{3}{*}{ Mode of acquiring tetanus } & Otogenic & $5(6.4 \%)$ \\
\hline & Post injury & $44(57.1 \%)$ \\
\hline & Unknown & $28(36.3 \%)$ \\
\hline \multirow{3}{*}{ Common symptoms } & Truisms & 77 (100\%) \\
\hline & Dysphagia & 70 (90\%) \\
\hline & Body stiffness/spasm & $65(84.4 \%)$ \\
\hline \multirow{4}{*}{ Grade of Severity } & 1 & $0(0 \%)$ \\
\hline & II & $21(27.2 \%)$ \\
\hline & III & $40(51.9 \%)$ \\
\hline & IV & $16(20.7 \%)$ \\
\hline \multirow{2}{*}{ Outcome } & Survived & $62(80.5 \%)$ \\
\hline & Expired & $15(19.5 \%)$ \\
\hline \multirow{4}{*}{ Length of stay } & $1-10$ days & $4(5.1 \%)$ \\
\hline & $11-20$ days & $16(20.7 \%)$ \\
\hline & 21-30 days & $52(67.5 \%)$ \\
\hline & $>31$ days & $5(6.4 \%)$ \\
\hline \multirow{5}{*}{ Complications } & LRTI (lower respiratory tract infection & $15(19.4 \%)$ \\
\hline & Hypotension & $25(32.4 \%)$ \\
\hline & AKI & $15(19.4 \%)$ \\
\hline & Sepsis & $18(23.3 \%)$ \\
\hline & Paralytic ileus/constipation & 35 (45.4\%) \\
\hline
\end{tabular}




\section{DISCUSSION}

In the current study, tetanus was found to be most common in the 2-7 year age group, which is also shown by Tulu M.S et al from Mumbai India. ${ }^{26}$ Naseem $\mathrm{F}$ et al found maximum tetanus patients in 2-6 years of age in Karachi Pakistan which again well correlates with our findings. ${ }^{27}$

Male predominance (80\%) was seen because the boys are more involved in outdoor activates as compared to girls. ${ }^{5}$ Contrary to this Naseem $\mathrm{F}$ et al showed almost equal ratio of male and female tetanus patients a PICU of Karachi Pakistan although more males were noted in post trauma cases. ${ }^{27}$ Narang $\mathrm{M}$ et al from Delhi showed $62 \%$ males in post neonatal tetanus patients. ${ }^{28}$

As far as portal of entry is concerned, Otogenic route was exclusively confined to the 2-7 year age group $(n=5,6.4 \%)$ as otitis media is mostly seen in this age group. Introduction of unclean fingers and contaminated objects into the ears is also common in this age. ${ }^{10}$ Naseem $F$ et al showed almost same age group for high frequency of otitis media as portal of entry. ${ }^{27}$ Narang $M$ et al from Delhi showed a very high frequency (60\%) of ear discharge in post neonatal cases. ${ }^{28}$

Regarding the vaccination status, 25 cases were unvaccinated, 52 were partially vaccinated (only BCG \& OPV at birth) and none was appropriately vaccinated for age. Naseem $F$ et al also showed high frequency of unvaccinated (73\%) and partially vaccinated (26\%) children. ${ }^{27}$ It seems to be the reflection of poor coverage of our immunization programmed in our country. In adult studies in Pakistan Talpur A et $\mathrm{al}^{29}$ showed $48 \%$, Muazzam $M$ et $\mathrm{al}^{30}$ showed $76 \%$ cases who were unimmunized or unaware of the immunization status. Unlike other diseases, tetanus is entirely preventable by immunization. ${ }^{31}$ A five dose regimen of tetanus taxied provides adequate immunity. Routine tetanus booster vaccination is recommended for adolescents and adults, every 10 years. ${ }^{32}$ It was noted that none of our patients was vaccinated for tetanus, which is very alarming because despite the continuous efforts of health sector, vaccination status of our children in general is falling and currently it is approx. 54\% (for all vaccine preventable diseases). ${ }^{33}$ Since Pakistan is an agricultural state and the disease is common where soil is cultivated, in rural areas, warm climates and among males, so being a tetanus prone country, vaccination against tetanus is imperative for our children. ${ }^{5}$

In our study we found truisms in all cases, dysphagia in $70(90 \%)$ and body stiffness in $65(84 \%)$. These findings are consistent with a lot of other reported studies. ${ }^{5,18,19,26,34}$ Hence a high index of suspicion for tetanus should be exercised whenever patients present with any of these symptoms irrespective of history of trauma. ${ }^{5}$

There are many scoring systems for grading the severity of tetanus. We adopted the Ablettclassification. ${ }^{35}$ In our study we found that our patients $40(51.9)$ were in grade III, $21(27.2 \%)$ grade 11 and $16(20.7 \%)$ in grade $1 \mathrm{~V}$. Our findings are consistent with Naseem at el ${ }^{26}$ that also had minimum grade III cases. It may be due to the fact that less severe cases are often treated in primary and secondary health care systems and are referred infrequently. Regarding the length of stay $52(67.5 \%)$ had a prolonged stay of 20-30 days. Tetanus patients usually require lengthy ICU stay. As proved by our study and supported by previous other studies, the longer the duration of hospital stay, the more favorable theoutcome. ${ }^{34}$

Autonomic dysfunction is common in tetanus. ${ }^{36-38}$ It usually starts by the end of 1st week of illness and persists for 1-2 weeks. It is due to the effect of tetanus toxin on the brain stem and autonomic interneurons. Although it is mainly due to paroxysmal increases in sympathetic activity resulting in hypertension, tachycardia and pyrexia, at times there is parasympathetic over activity resulting in hypotension and bradycardia added by heavy doses of benzodiazepines and othersedatives. ${ }^{39}$ In our study we found autonomic dysfunction in $20.7 \%$ (16) of cases and these contributed to maximum mortality. In an adult study in Pakistan the autonomic dysfunction was found to be $12 \% .{ }^{29}$ Paralytic illus was seen strikingly high in our sudy $45.4 \%$ as compared to other local study in Pakistan $13 \% .{ }^{29}$ Hypotension was found in $25(32.4 \%)$ cases all 
of which needed inotropic support to maintain BP between50th and 90th centile. It was much less than found by Naseem et al which showed $73.91 \%$ cases developing hypotention. ${ }^{27}$

Regarding the outcome, tetanus has a mortality rate ranging between 20 to over $50 \%$ as mentioned in variousstudies. ${ }^{5,19,26,27,37,40}$ Mortality rate was $19.5 \%(15)$ in our study and $80.5 \%(62)$ cases survived. In another study in Pakistan the mortality rate was $26 \% .27$ Most of the cases with grade IV severity, having severe autonomic instability and respiratory compromise needing mechanical ventilation expired.

\section{CONCLUSION}

Tetanus is a fatal disease with high mortality rate. Complete vaccination and proper management of the diseased cases are the best options to reduce the burden of tetanus in our country.

\section{Copyright@ 20 June, 2019.}

\section{REFERENCES}

1. Wasay M, Khatri IA, Salahuddin N. (Editorial) Tetanus and rabies eradication in Pakistan; a mission not impossible. J Pak Med Assoc 2008; 58(4):158-9.

2. Khaskheli MS, Khuhro BA, Jamali AH. Tetanus: Still a killer in adults. Anesth, pain \& intensive care 2013; 17(2):149-153.

3. Blencowe H, Lawn J, Vandelaer J, Roper M., Cousens $\mathrm{S}$. Tetanus toxoid immunization to reduce mortality from neonatal tetanus. Int J Epidemiol 2010; 39: I102I109.

4. Brook I. Tetanus in children. Pediatric Emergency Care. 2004; 20:48-51.

5. Lan LG, Kong Ko, Chew PH. A ten year retrospective study of tetanus at a general hospital in Malaysia. Singapore Med J. 2001; 42(8):346-350.

6. Edlich RF, Hill LG, Mahler CA, Cox MJ, Becker DG, Horowitz $\mathrm{JH}$ : Management and prevention of tetanus. J Long Term Eff Med Implants 2003; 13(3):139-54.

7. Younas NJ, Abro AH, Das K, Abdou AMS, Ustadi AM, Afzal S: Tetanus: Presentation and outcome in adults. Pak J Med Sci 2009; 25(5):760-5.

8. Tejpratap SP, Tiwari MD. Tetanus. In: Sandra WR, Lynne $M$, Linda MB, editors. Manual for the surveillance of vaccine preventable diseases. 5th ed. Atlanta, GA: Centre for Disease Control and prevention; 2011. pp.1-6.
9. Weng WC, Huang WY, Peng TI, Chien YY, Chang KH., RoLS, Lyu RK, Wu CL. Clinical characteristics of adult tetanus a Taiwan medical center. J Formos Med Assoc 2011; 10:705-10.

10. Hassel B. Tetanus: Pathophysiology, treatment, and the possibility of using botulinum toxin against tetanus-induced rigidity and spasms. Toxins (Basel) 2013; 5:73-83.

11. Mishra K, Basu S, Kumar D, Dutta AK, Kumar P, Rath B. Tetanus - still a scourge in the 21st century: A pediatric hospitalbased study in India. Trop Doct 2012; 42:157-9.

12. Amare A, Melkamu $Y$, Mekonnen D. Tetanus in adults: Clinical presentation, treatment and predictors of mortality in a tertiary hospital in Ethiopia. J NeurolSci 2012; 317:62-5.

13. Brian SS, Henry FC. Bacterial, Chlamydial Infections. In: Stephen JM, Maxine AP, editors. Current Medical Diagnosis and Treatment. 48thed. McGraw Hill Lange; 2009:12656.

14. Brauner JS, Vieira SR, Bleck TP. Changes in severe accidental tetanus mortality in the ICU during two decades in Brazil. Intensive Care Med 2002; 28(7):9305 .

15. Wasay M, Khealani BA, Talati N, Shamsi R, Syed NA, Salahuddin N. Autonomic nervous system dysfunction predicts poor prognosis in patients with mild to moderate Tetanus. BMC Neurol 2005; 5(1):2.

16. Beeching NJ, Crowcroft NS. Tetanus in injecting drug users. BMJ. 2005; 330(7485):208-9.

17. Sutiono AB, Qiantoria A, Suwa H, Ohta T. Characteristic tetanus infection in disaster affected areas: case study of the Yogyakarta earth quakes in Indonesia. BMC Res Notes. 2009; 2:34.

18. Aceh epidemiology group. Outbreak of tetanus cases following the tsunami in Aceh Province, Indonesia Glob Public Health. 2006; 1(2)173-177.

19. Khurram M, Mahmood N. Tetanus in post 2005 Pakistan earth quake scenario. J Coll Physicians Surg Pak. 2007; 17:577-8.

20. Wassila SGF, Roper MH, Kretsinger $\mathrm{K}$, Orenstein WA. Tetanus toxoid. In: Plotkin SA, Orenstein WA, Offit PA, eds. Vaccines 5th edition Philadelphia: Saunders; 2008:805-9.

21. World epidemiological record. Tetanus vaccine: WHO position Paper. 2006; 81:197-208. 
22. Ahmed SI, Baig L, Thaver IH, Siddqui MI, Jafery SI, Javed A. Knowledge, attitudes and practices ofgeneral practitioners in Karachi District Central about tetanus immunization in adults. J Pak Med Assoc 2001; 51:367-9.

23. Zeb A, Zaidi SA, Jehan I. Knowledge, attitude and practices of reproductive age females about tetanus toxoid vaccine: A pilot study. J Coll Physicians SurgPak 2006; 16:791-3.

24. Afridi NK, Hatcher J, Mahmud S, Nanan D. Coverage and factors associated with Tetanus Toxoid vaccination status among females of reproductive age in Peshawar. J Coll Physicians Surg Pak 2005; 15:391-5.

25. Raza MA, Abbas MH. Tetanus disease patterns observed in a specialized unit. J Coll Physicians SurgPak 2000; 10:249-54.

26. Tullu M.S, Deshmukh CT, Kamat JR. Experience of pediatric tetanus cases from Mumbai. Indian Pediatr. 2000; 37:765-71.

27. Naseem F, Mahar IA, Arif F. Two years' study of Tetanus cases in a Pediatric Intensive Care Unit. Pak J Med Sci. 2016; 32(3):641-645.

28. Narang M, Khurana A, Gomber S, Choudhary N. Epidemiological trends of tetanus from East Delhi, India: a hospital-based study. J Infect Public Health. 2014 Mar-Apr; 7(2):121-4.

29. Talpur AA, Surahio AR, Memon AS, Junejo A, Jamal A. Tetanus situation in Pakistan; comparison of medical versus surgical management. Professional Med J 2016; 23(6):634-40.

30. Muazzam M, Mansoor SA, Badar S, Nadeem A, Anwar B, Waseer MH, Ali S. Tetanus; still cannot be prevented, a three year retrospective study in DHQ hospital, Faisalabad. Professional Med J 2013; 20(6):1026-34.
31. CDC. Tetanus surveillance. United states, 2001-2009. MMWR. 2011; 60:365-96.

32. CDC. General Recommendations on Immunization. Recommendations of the advisory committee on immunization practices (ACIP) MMWR 2011; 60(noRR2):3-60.

33. Pakistan demographic health survey 2012-2013.32. Ablett JJL. Analysis and main experiences in 82 patients treated in the Leeds tetanus unit. In: Ellis $M$, editor. Symposium on tetanus in Great Britain. Boston Spa, UK: Leeds general infirmary, 1967.p.1-10.

34. Fawibe AE. The pattern and outcome of adult tetanus at a sub-urban tertiary hospital in Nigeria. J Coll Physicians Surg Pak. 2010; 20(1):68-70.

35. Cook TM, Protheroe RT, Handel JM. Tetanus: a review of the literature. Br J Anaesthesia. 2001; 86:477-87.

36. Turton K, Chaddock JA, Acharya KR. Botulinum and tetanus nerurotoxins; structure, function and therapeutic utility. Trends Biochem Sci. 2002; 27:552558.

37. Singhi S, Jain V, Subramanian C. Post-neonatal tetanus: Issues in intensive care management. Indian J Pediatr 2001; 68(3)267-72.

38. Oladiran I, Meler DE, Ojelade AA, Olaolorum DA, AdeniranA, Trapley JL. Tetanus continuing problem in the developing world. World J Surg. 2002; 26:12821285.

39. Hsu SS, Grolean G. Tetanus in the emergency department: A current review. J Emerg Med. 2001; 20 (4):357-65.

40. Mahsud IU, Khan HU, Khattak AM, Wazir FU, Shah SH. Mortality rate in adult tetanus patients in district D.I.Khan, NWFP Pakistan. Biomedica. 2005; 21:86-89.

\begin{tabular}{|c|l|l|l|}
\hline \multicolumn{3}{|c|}{ AUTHORSHIP AND CONTRIBUTION DECLARATION } \\
\hline Sr. \# & \multicolumn{1}{|c|}{ Author(s) Full Name } & \multicolumn{1}{|c|}{ Contribution to the paper } & Author(s) Signature \\
\hline 1 & Asim Khurshid & $\begin{array}{l}\text { Idea, Methodology, Data } \\
\text { Collection, Data analysis. } \\
\text { Literature review, Proof } \\
\text { reading. } \\
\text { Methodology, Literature review, } \\
\text { Discussion. } \\
\text { Proof reading, Supervision. }\end{array}$ \\
\hline 4 & Muhammad Amin & Muhammad Tariq Aziz & Lqu \\
\hline
\end{tabular}

